\title{
Migração de depocentros na Bacia de Santos: importância na exploração de hidrocarbonetos
}

\author{
Mário Luis Assine ${ }^{1}$, Fernando Santos Corrêa ${ }^{2}$ \& Hung Kiang Chang ${ }^{1}$
}

\begin{abstract}
Resumo Recentes descobertas de petróleo atraíram a atenção para a Bacia de Santos, localizada na região sudeste da costa brasileira. A bacia está situada a sul da Bacia de Campos, a mais prolífera província de petróleo do Brasil. As bacias são separadas pelo alto de Cabo Frio e apresentam muitas similaridades na evolução estrutural e estratigráfica. A seção terciária é bem desenvolvida em ambas as bacias, porém os registros do Cretáceo superior são significativamente mais expressivos na Bacia de Santos, representados por espessas cunhas clásticas progradacionais formadas do Santoniano ao Maastricthiano. Espaço de acomodação foi gerado pela retirada do sal e sua migração em direção as porções de águas profundas da bacia, com rafting das seqüências carbonáticas albianas e deposição de folhelhos marinhos com intercalações de turbiditos Ilhabela no Cenomaniano-Turoniano. Devido ao deslocamento dos evaporitos aptianos, cunhas clásticas progradacionais sobre a discordância pré-aptiana colocaram em contato rochas geradoras da seqüência rifte com rochas reservatórios do Cretáceo superior. O sal continuou em movimento, mas seu maior deslocamento ocorreu durante o Neo-Cretáceo, não tendo sido a progradação das clinoformas simultânea ao longo da bacia. Para entender o arcabouço estratigráfico das seqüências deposicionais e migração de seus depocentros, foi realizada análise estratigráfica utilizando dados de sísmica 2D e de poços. Mapas de isópocas e de razões litológicas foram construídos com base em 60 poços, os quais mostraram claramente migração dos depocentros para nordeste no Neo-Cretáceo, em direção a Bacia de Campos, onde a seção terciária é melhor desenvolvida. Na parte norte da Bacia de Santos, a seção terciária inferior é caracterizada pela existência de proeminentes progradações deltaicas associadas a sistemas turbidíticos. Um outro importante depocentro terciário está localizado na parte sul da bacia, onde sistemas de águas profundas foram reconhecidos em seções sísmicas, ainda não perfurados. O reconhecimento do caminho da migração dos depocentros é um importante guia geológico para a exploração de óleo e gás, porque permite interpretações acerca da idade da formação de rochas reservatório e do tempo de migração dos hidrocarbonetos.
\end{abstract}

Palavras-chave: Bacia de Santos, migração de depocentros, estratigrafia de seqüências, exploração petróleo.

\begin{abstract}
Depocenter migration in the Santos Basin: importance to oil and gas exploration. Recent important discoveries of gas and oil fields during the last few years have called attention to the Santos Basin, offshore Southeast Brazil. The basin is located south of the Campos Basin, the most prolific Brazilian oil province. The Cabo Frio Arch is the frontier between them, but the two basins present many similarities in their structural and stratigraphic evolution. Meanwhile, the Upper Cretaceous record is significantly more preserved in the Santos Basin, being characterized by thick Santonian to Maastrichtian progradational siliciclastic clinoforms. The accommodation space was generated by salt basinward withdrawal, which in consequence caused the rafting of the Albian Guarujá carbonate sequences and of the deposition of Cenomanian to Turonian marine shales and Ilhabela turbidites. Because of the withdrawal of Aptian transitional evaporites and rafted younger sequences, the deltaic clastic wedges downlap the pre-Aptian unconformity, placing in contact Upper Cretaceous reservoirs with Lower Cretaceous rift source-rocks. Progradation was not simultaneous along the basin and resulted from migration of sediment input along the Brazilian margin. In order to understand the way of depocenter migration, a sequence stratigraphic analysis was carried out using available seismic lines and well data. The sequence boundaries were traced in 60 wells, and isopach and several lithologic ratio maps were produced for each sequence. The maps show clearly a depocenter migration towards northeast during the Late Cretaceous along the Santos Basin into the Campos Basin, where the Tertiary section is well developed. Early Tertiary section is well developed in the north portion of the Santos Basin, represented by prominent deltaic progradation and associated turbidite systems. Another important Tertiary depocenter is placed in the southmost portion of the Santos Basin, where deep-water systems were recognized in seismic sections. The recognition of the pathway of depocenter migration is an important guide to oil and gas exploration, since it support interpretation concerning the relation between the formation of reservoir rocks and the timing of petroleum generation and migration.
\end{abstract}

Keywords: Santos Basin, depocenter migration, sequence stratigraphy, petroleum exploration

1 - Departamento de Geologia Aplicada, Universidade Estadual Paulista - UNESP, Rio Claro - SP, Brasil

E-mail: assine@rc.unesp.br, chang@rc.unesp.br

2 - UNESP, Programa de Pós-Graduação em Geociências e Meio Ambiente, Rio Claro - SP, Brasil. E-mail: fscorrea@rc.unesp.br 
INTRODUÇÃO A Bacia de Santos localiza-se na margem continental da Região Sudeste do Brasil, tendo limite norte com a Bacia de Campos definido pelo Alto de Cabo Frio e limite sul com a Bacia de Pelotas definido pela Zona de Fratura de Florianópolis (Fig. 1). Sua geologia está sintetizada na carta estratigráfica da figura 2, que apresenta informações lito e cronoestratigráficas, ilustra a arquitetura estratigráfica das diferentes unidades, e fornece informações sobre os ambientes sedimentares, sobre as seqüências deposicionais e a respeito das fases da evolução tectônica da bacia. A carta, de autoria de Pereira \& Feijó (1994), foi utilizada em diferentes publicações e adotada como carta padrão pela ANP e pela Petrobrás, sendo utilizada neste trabalho com pequenas modificações.

No que concerne à geologia do petróleo, recentes descobertas como a de gás em arenitos do Senoniano (campo de Mexilhão, por exemplo) e de óleo em calcários da seção pré-sal (campo de Tupi, por exemplo), têm evidenciado o alto potencial petrolífero da bacia, justificando o grande investimento exploratório que diversas companhias tem feito nos últimos anos.

O grande número de novos levantamentos sís- micos e a crescente qualidade dos dados têm contribuído sobremaneira para o sucesso exploratório. De outra parte, novos conceitos e novas concepções acerca da evolução tectono-sedimentar e do preenchimento da bacia estão abrindo novas perspectivas e gerando novos modelos de migração e acumulação. Neste aspecto, a compreensão da tectônica salina e do conseqüente movimento das camadas de sal, carregando espessas seções de carbonatos albianos, a elas sobrepostos, num transporte do tipo rafting em direção às partes mais profundas da bacia, constituem atualmente temas dos mais importantes na formulação de plays exploratórios.

Durante as duas últimas décadas, inúmeros trabalhos apresentaram dados e interpretações sobre a dinâmica da movimentação do sal e conseqüente formação de estruturas na Bacia de Santos. Uma das feições estruturais mais notáveis é conhecida como falha de Falha de Cabo Frio, uma estrutura de estrutura de geometria lístrica mergulhante para o continente, com muralhas de sal de idade aptiana no bloco alto. O sal é praticamente ausente no bloco baixo, onde a seção do Cretáceo superior apresenta estruturas do tipo rollover. Demercian et al. (1993) interpretaram que tal configura-

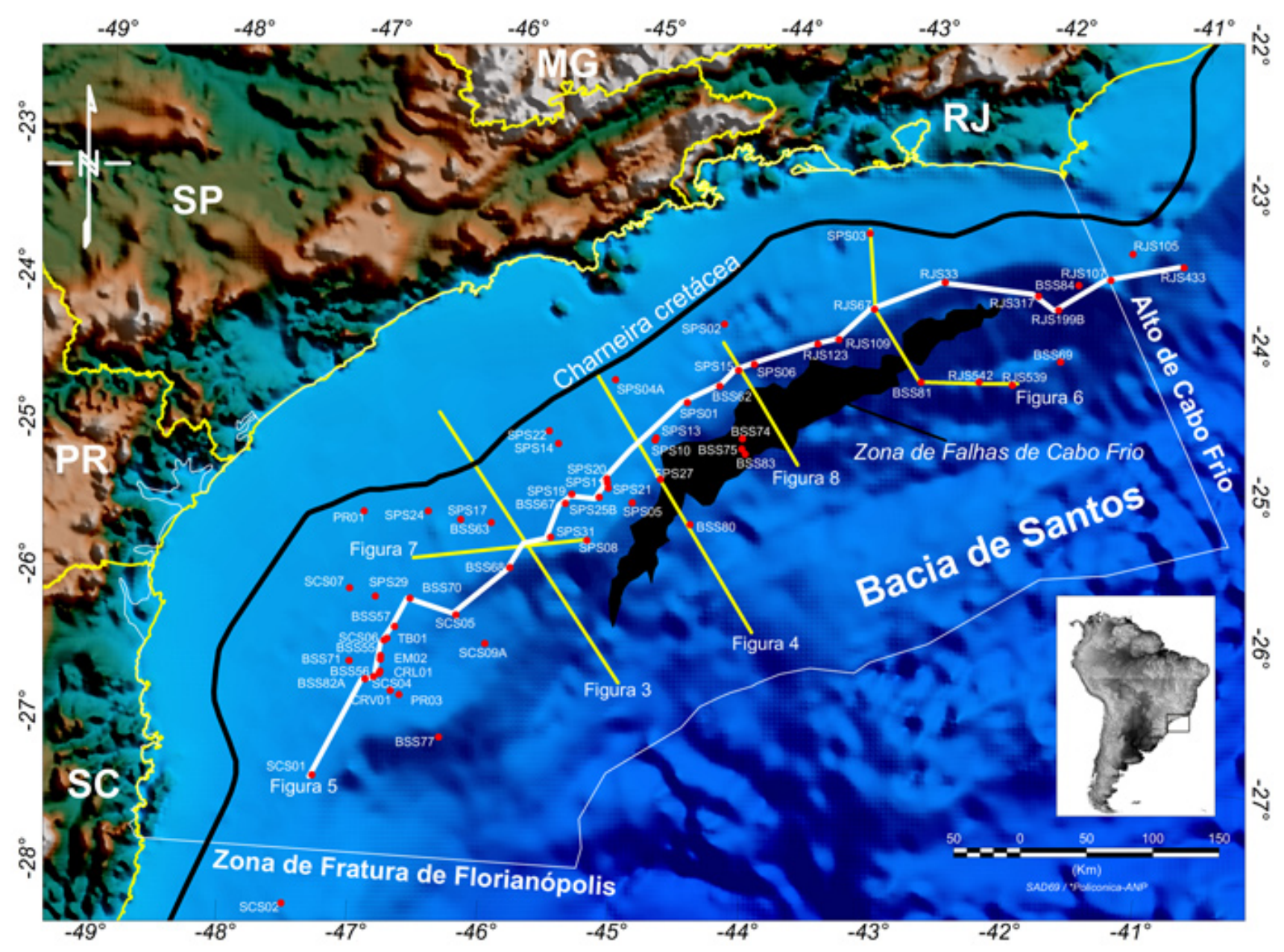

Figura 1 - Mapa de localização da Bacia de Santos, com indicação das seções apresentadas em outras figuras. A área onde o Albiano se encontra ausente (albian gap), situada no bloco baixo da Zona de Falhas de Cabo Frio, está indicado em preto. 


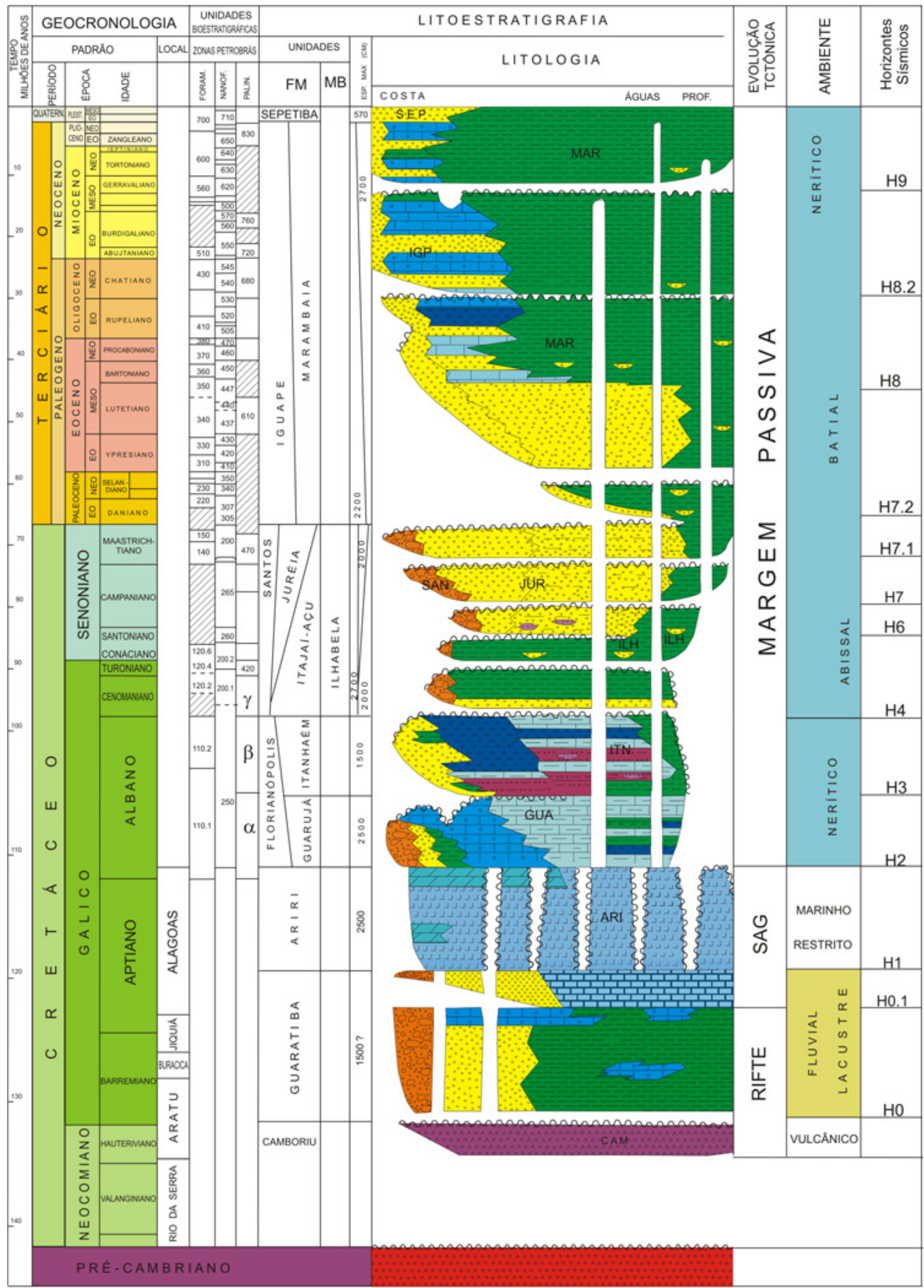

Figura 2 - Carta estratigráfica da Bacia de Santos (modificado de Pereira \& Feijó 1994). Discordâncias apresentadas na ultima coluna da direita referem-se aos limites das seqüencias discutidas neste trabalho. A discordância H0.1 corresponde à discordância pré-Alagoas. 
ção resultou de tectônica distensiva na porção proximal da bacia, responsável pelo rompimento e deslocamento do sal e da seção carbonática albiana sobreposta.

Para a formação de configurações como a acima delineada, o papel desempenhado pelo avanço de cunhas clásticas não pode ser olvidado. Ao analisar várias hipóteses para explicar a formação do gap albiano, Mohriak et al. (1995) concluiram que as estruturas associadas à falha de Cabo Frio resultaram da combinação de tectônica distensiva e de progradação de cunhas siliciclásticas. Segundo Szatmari et al. (1996), as estruturas rollover foram produzidas devido ao arqueamento de cunhas progradacionais do Cretáceo superior durante o deslocamento do sal em direção às partes mais profundas da bacia. Com a movimentação da falha, houve a formação de um gap lateral da seção albiana, de cerca de $25 \mathrm{~km}$ de largura, ao longo de todo o bloco baixo da falha.

Mais que simplesmente um agente coadjuvante, Ge et al. (1997) postularam que a falha de Cabo Frio e estruturas relacionadas resultaram principalmente da progradação de cunhas siliciclásticas, com deslocamento do sal e da seção albiana superposta, e arqueamento das cunhas gerando estruturas rollover. Colocando a palavra falha entre aspas, chegaram mesmo a questionar que a falha de Cabo Frio é realmente uma falha gerada por tectônica distensiva, pois em simulações com modelos físicos conseguiram reproduzir feições semelhantes produzidas unicamente pela sobrecarga induzida pelo aporte sedimentar.

A sobrecarga sedimentar derivada da progradação de clinoformas deposicionais foi fator realmente importante como agente causador do descolamento e movimento offshore do sal, e rafting da seção albiana superposta, de natureza dominantemente carbonática e pertencente às formações Gurarujá e Itanhaém. Outro aspecto importante a ser considerado é que o processo foi diácrono ao longo do strike deposicional da Bacia de Santos em decorrência de mudanças na paleodrenagem continetal, que sofreu influências de pulsos tectônicos relacionados ao soerguimento da Serra do Mar. Capturas de rios, relatadas em vários trabalhos sobre a geomorfologia do Planalto Atlântico, constituem fator importante para a compreensão do preenchimento sedimentar da bacia, como a do rio Paraíba do Sul, já considerada nos trabalhos de Cobbold et al. (2001) e de Modica \& Brush (2004).

Grandes clinoformas progradacionais estão presentes em todo o Cretáceo superior da Bacia de Santos, delineando arcabouço estratigráfico peculiar. As cunhas clásticas que compõe as formações Santos e Juréia, e a parte superior da Formação Itajaí-Açu, não tem paralelo na Bacia de Campos, onde o registro do Cretáceo superior é bem menos expressivo.

A fisiografia da Bacia de Santos tornou-se diferente no Cenozóico, com o desenvolvimento de plataforma continental e talude bem definidos, o que propiciou a formação de depósitos em contexto de bacia profunda. A presença de construções recifais de borda de plataforma também contribuiu para que os depósi- tos cenozóicos estejam organizados numa arquitetura estratigráfica distinta do padrão apresentado pelo Cretáceo superior. Embora distintas das cretáceas, clinoformas progradacionais continuaram a ser os principais responsáveis pelo preenchimento da bacia, registrando diferentes sentidos de afluxo sedimentar derivado do continente.

Este trabalho tem por objetivos sumariar as características das seqüências deposicionais da bacia, do Cretáceo superior ao Recente, e apresentar um panorama geral no sentido de estabelecer a variação da localização dos seus depocentros ao longo do tempo geológico. Além disso, também constitui objetivo verificar como o entendimento da progradaçao das clinoformas e da migração dos depocentros pode servir como guia para a exploração de hidrocarbonetos na bacia.

ANÁLISE ESTRATIGRÁFICA Os fundamentos da subdivisão da sucessão sedimentar da Bacia de Santos em seqüências deposicionais foram apresentados no trabalho de Pereira et al. (1986), que fundamentaram suas interpretações no rastreamento de horizontes sísmicos marcantes, no geral discordâncias regionais ( $\mathrm{H} 0$ a H10). Por considerarem que os horizontes rastreados eram discordâncias, os referidos autores interpretaram as seções estratigráficas entre os horizontes como seqüências deposicionais, a saber: H0-H1 = Seqüência do Lago (Buracica? / Alagoas); H1-H2 = Seqüência do Golfo (Alagoas); H2-H3 = Eo-Meso-Albiano; H3-H4 = Neo-Albiano / Cenomaniano; H4-H5 = Cenomaniano / Meso-Turoniano; H5-H6 = Neo-Turoniano / Eo-Santoniano; H6-H7 = Santoniano / Eo-Campaniano; H7-H8 = Campaniano / Eo-Eoceno; H8-H9 = Eo-Eoceno / Meso-Mioceno; e H9-H10 = Meso-Mioceno / Recente.

Procedimento análogo foi adotado na análise estratigráfica realizada neste trabalho, buscando-se reconhecer os horizontes (superfícies-chave) e fatiar conjuntos de estratos geneticamente associados, que representam o registro sedimentar da sucessão de eventos deposicionais na bacia. A análise seqüencial foi baseada fundamentalmente em métodos sismoestratigráficos e de correlação estratigráfica de dados de poços. Na interpretação das seções sísmicas foram rastreados, além dos horizontes definidos por Pereira et al. (1986), outros cinco horizontes (H0.1, H7.1, H7.2, H8.1, H8.2).

Para verificar a representatividade e a continuidade lateral dos horizontes, foram interpretadas 10 seções na direção do mergulho estrutural da bacia, perpendiculares portanto às curvas batiméticas, duas das quais estão apresentadas nas figuras 3 e 4 . O reconhecimento geológico dos horizontes sísmicos teve como base a amarração ao registro geológico de poços, tendo sido considerados dados litológicos, perfis geofísicos e dados cronoestratigráficos.

A interpretação das seções sísmicas foi feita paralela e concomitantemente à de seções de correlação estratigráfica construídas com dados de poços. Foram confeccionadas várias seções dip e uma extensa seção strike regional, do limite sul com a Bacia de Pelotas até o limite norte com a Bacia de Campos, amarrando todas 


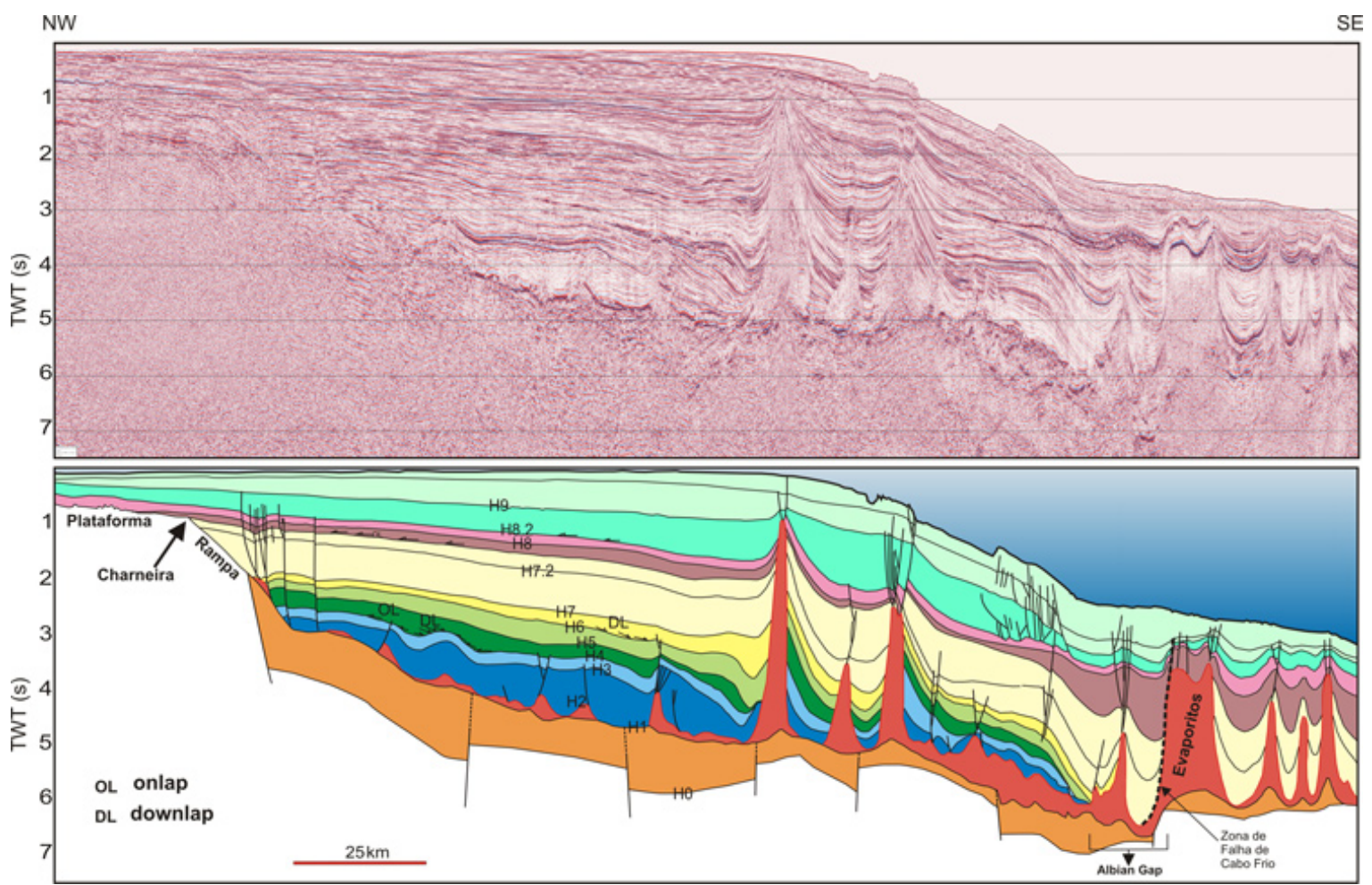

Figura 3 - Seção sísmica dip na área central da bacia, na qual pode ser observada a linha de charneira do Cretáceo.
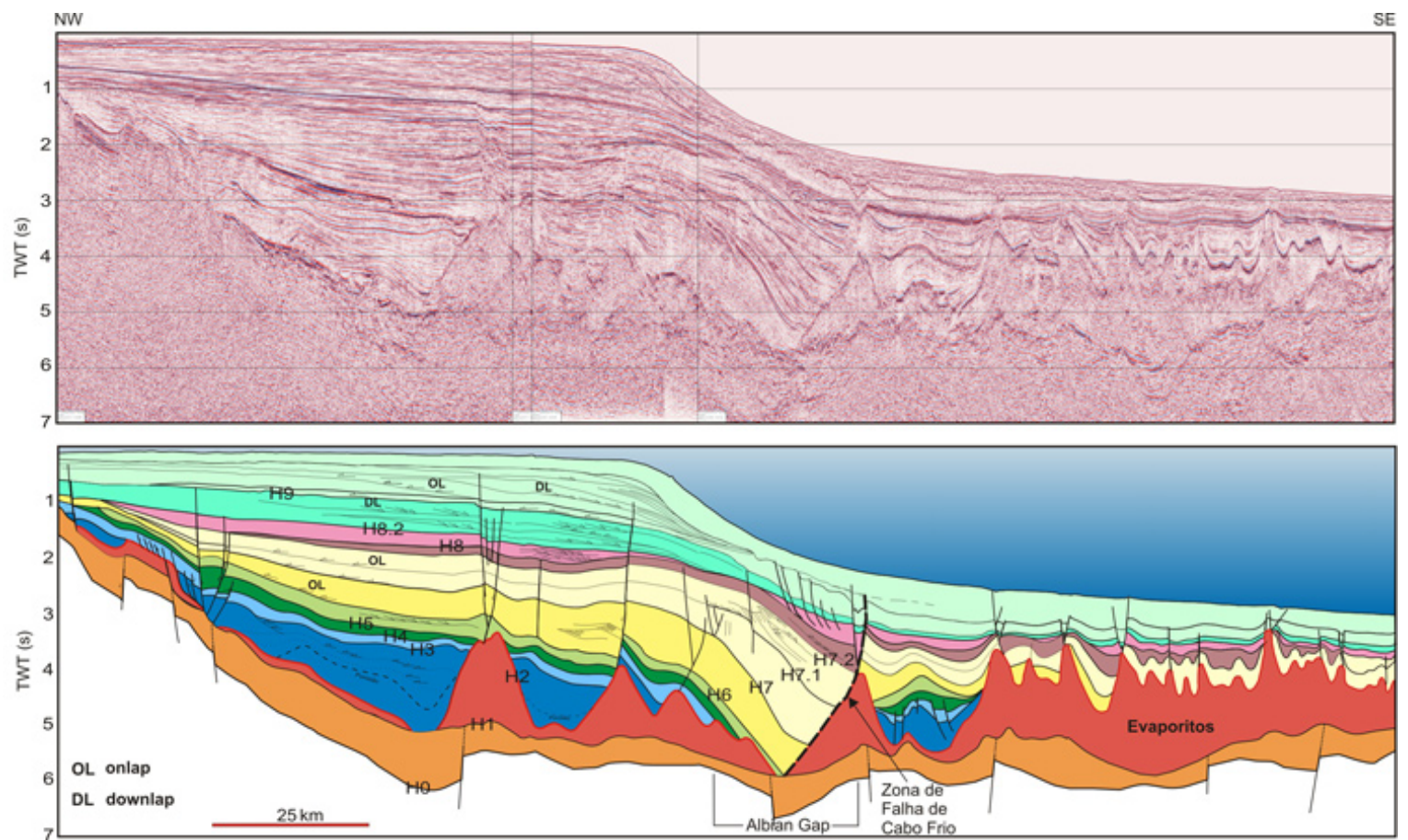

Figura 4 - Seção sísmica dip na área central da bacia. Destacam-se nesta seção a existência de seção albiana descolada e transportada por rafting mergulho deposicional abaixo, de clinoformas clásticas do Cretáceo superior rotacionadas devido ao movimento do sal, e de seção terciária com grande espessura. 
as seções dip. No intuito de tentar reconhecer os trends na parte norte da Bacia de Santos, foi incluído, na seção strike, o poço RJS- 433, perfurado na parte sul da Bacia de Campos (Fig. 5).

$\mathrm{Na}$ análise de perfis de poços, foi fundamental reconhecer as superfícies-chave para que a análise não ficasse restrita à identificação de contatos entre unidades litoestratigráficas. O perfil sônico revelou-se particularmente útil na análise dos poços, pois foi possível correlacionar mudanças bruscas nos padrões de tempo de trânsito (diferenças na velocidade de propagação do som) com as superfícies-chave. Correlações calcadas em perfis como o de raios-gama foram também utilizadas e forneceram subsídios importantes às interpretações. Foram, porém, utilizados com cautela, pois não têm necessariamente significado cronoestratigráfico, uma vez que o padrão dos perfis é condicionado pelas mudanças laterais de fácies, reflexo da justaposicão lateral de ambientes deposicionais, tanto na direção strike quanto no mergulho deposicional.

As superfícies-chave reconhecidas nas seções sísmicas constituem discordâncias importantes no registro estratigráfico, embora algumas gradem para conformidades nas porções distais da bacia (talude e bacia profunda). Tais superfícies aparecem nas seções sísmicas como refletores bem marcados e com boa continuidade lateral, aos quais se associam terminações estratais importantes, como downlap e onlap.

Com base nas discordâncias identificadas e considerando a escala de trabalho, a sucessão sedimentar da Bacia de Santos foi subdividida em 13 seqüências deposicionais (Fig. 2), que se mostraram reconhecíveis e rastreáveis em seções sísmicas

Os topos das formações Guaratiba, Ariri, Guarujá e Itanhaém coincidem, respectivamente, com os discordâncias H1, H2, H3 e H4, de forma que nestes casos os topos das unidades litoestrtigráficas coincidem com os limites das seqüências.

Nem sempre, entretanto, os limites das unidades litoestratigráficas são síncronos. As formações Santos e Juréia transicionam lateralmente, de forma que o contato entre ambas é arbitrário, por isso consideradas neste trabalho como uma só unidade. Seu topo é diácrono, marcado na primeira ocorrência de pacotes espessos de arenitos e/ou conglomerados, não tendo nenhum significado temporal (Fig. 6).

A arquitetura do Terciário revelou-se bem mais complexa do que a proposta no trabalho de Pereira et al. (1986), conseqüência do pouco interesse despertado pelo Terciário àquela época, em termos de exploração petrolífera da bacia. O que se verificou é que a evolução no Terciário também foi marcada por grandes cunhas clásticas (clinoformas) progradacionais, grandes oscilações do nível do mar e desenvolvimento de carbonatos de borda de plataforma. O discordância H9 é sem dúvida uma discordância regional, mas foi possível reconhecer uma outra superfície igualmente expressiva, denominada neste trabalho H8.2. A subdivisão do registro pós-Cretáceo em quatro seqüênciasdeposicionais atendeu plenamente ao objetivo de caracterizar a geologia cenozóica da bacia. Estas seqüências apresentam características muito distintas, o que permitiu estabelecer, em linhas gerais, a sucessão de eventos no Terciário.

Mapas de atributos estratigráficos foram confeccionados a partir de poços selecionados. A interpretação realizada poço-a-poço foi orientada por dados paleontológicos e, principalmente, por perfis geofísicos, devido à inexistência de informações paleontológicas em alguns poços. O universo amostral dos atributos es-

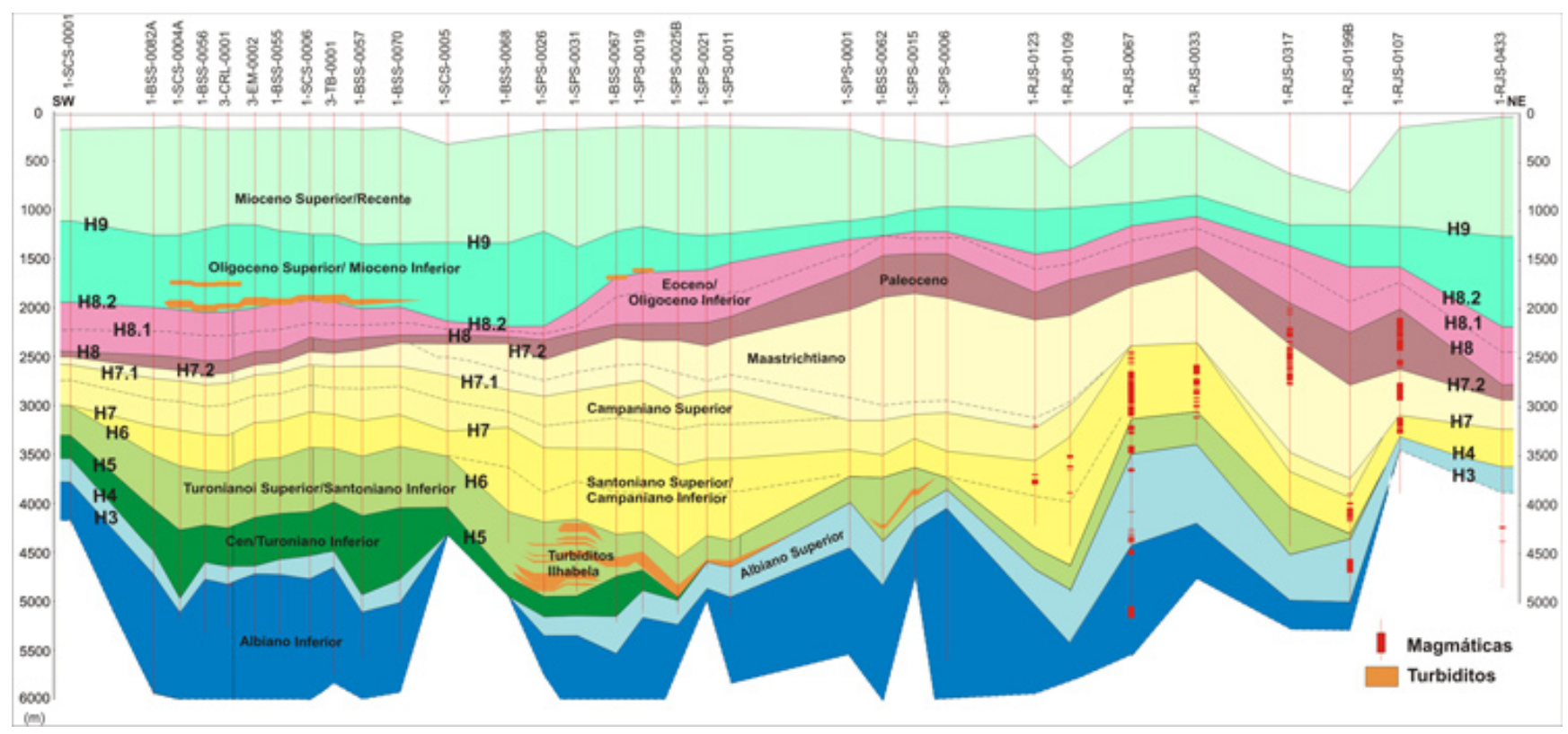

Figura 5 - Seção de correlação de poços no strike da bacia, na qual podem ser observadas as diversas seqüências deposicionais e a variação lateral de suas espessuras. 


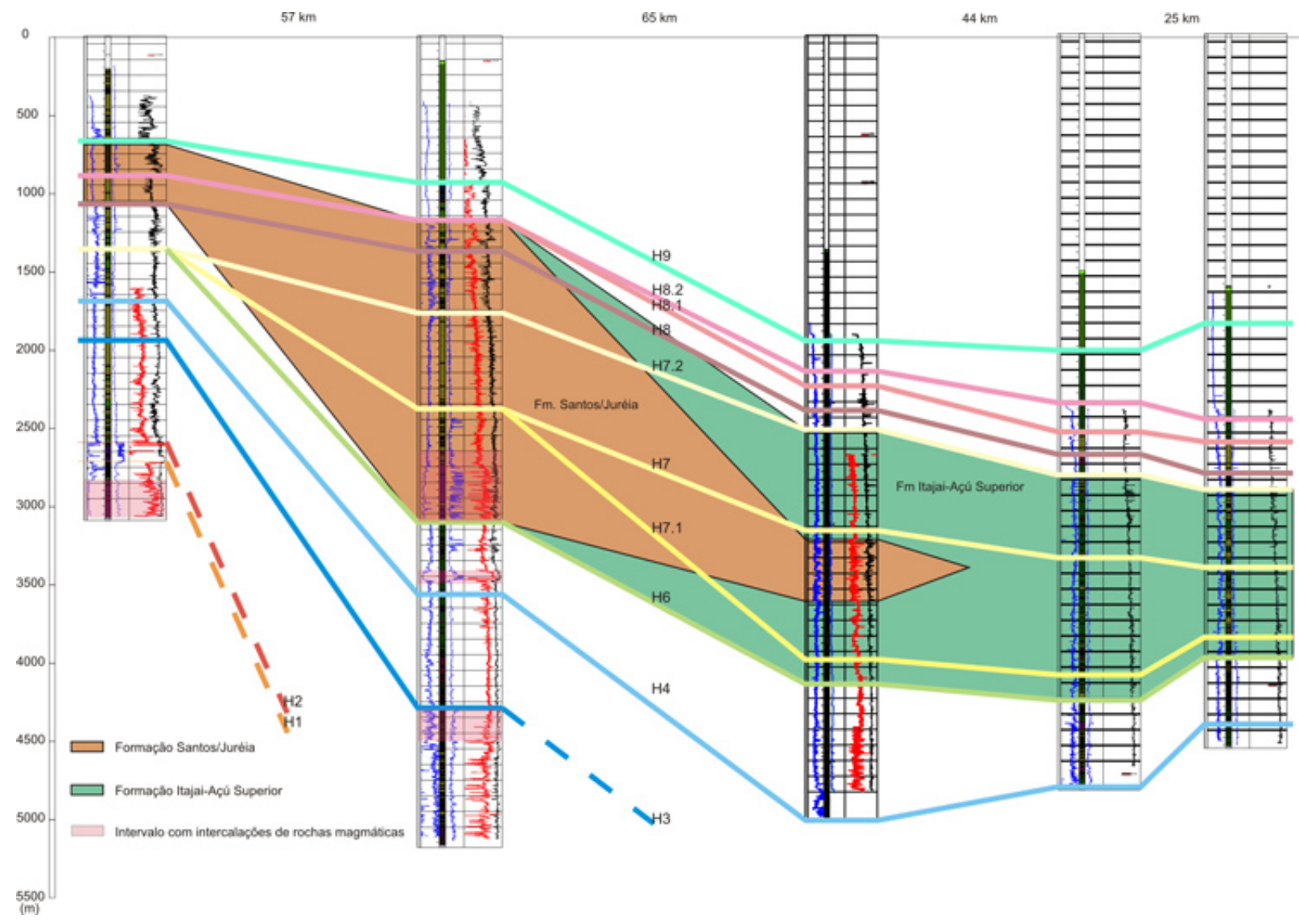

Figura 6 - Seção de correlação de poços na direção do mergulho deposicional (dip) da bacia. A seção mostra claramente o diacronismo do conjunto das formações Santos-Juréia, que se interdigita com a parte superior da Formação Itajaí-Açu.

tratigráficos teve boa representatividade em toda bacia, totalizando 61 poços distribuídos de forma homogênea e perfazendo uma cobertura de informações suficiente para a geração mapas (localização dos poços: Fig. 1). Vale ressaltar que todas as informações foram armazenadas em planilhas eletrônicas, a fim de facilitar a realização dos cálculos. A análise dos dados litológicos resultou na obtenção de 3 atributos: isópacas, isólitas e razões entre as diversas litologias encontradas nos intervalos estipulados. Para tanto, desenvolveu-se uma rotina de computador que realiza automaticamente a leitura dos arquivos do AGP (Arquivo Geral de Poços) e calcula, para cada intervalo de tempo, as espessuras das diferentes litologias.

A geração dos mapas de atributos foi realizada através de métodos geoestatísticos de interpolação, sendo utilizada a krigagem como interpolador. $\mathrm{O}$ modelo variográfico foi linearizado para todos os mapas a fim de simplificar a base de cálculo, já que não há grandes irregularidades nos dados. Somente o parâmetro de elipsóide da área de busca das informações foi ajustado, caso a caso, no intuito de otimizar e melhorar a interpolação, e gerar mapas com maior acuracidade nos contornos. Algumas peculiaridades de ordem estratigráfica foram atribuídas aos mapas, seguindo alguns critérios: para intervalos mais antigos que o Maastrichtiano, o limite do mapa se estende somente até a charneira, pois é verificado em seções sísmicas que os sedimentos do Cretáceo não ultrapassam a linha da charneira na direção oeste; outro critério de restrição, para o intervalo do Terciário até o presente, é que o limite oeste é a própria linha de costa, visto que em linhas sísmicas estes depósitos se estendem até a linha de costa atual; por fim, na porção mais a leste, para ambos intervalos, a restrição aplicada foi uma distância média de $50 \mathrm{~km}$ dos poços na direção leste, coincidindo com a cota batimétrica de $2000 \mathrm{~m}$.

SEQÜÊNCIAS DEPOSICIONAIS A bacia apresenta um arcabouço estratigráfico bastante complexo, resultado da superimposição de diversos eventos geológicos. Tais eventos encontram-se impressos no arcabouço estratigráfico da bacia, mas sua expressão é desigual, tanto em termos de magnitude quanto de representatividade, nos diferentes compartimentos estruturais da bacia. As seqüências consideradas neste trabalho apresentam arquitetura estratigráfica e padrões de preenchimento distintos, o que é bem ilustrado pelas seções apresentadas nas figuras 3,4 e 5 . As características das seqüências deposicionais da bacia, do Cretáceo superior ao Recente, são sumariadas a seguir, buscando-se fornecer informações que permitam compreender sua arquitetura estratigráfica e distribuição ao longo da bacia. 
Cenomaniano/Turoniano Inferior (H4-H5) A seqüência é composta dominantemente por uma seção litologicamente monótona de folhelhos marinhos escuros ricos em matéria orgânica, correspondente à parte inferior da Fomação Itajaí-Açu. Está muito bem representada na parte sul da bacia, onde pode ser rastreada continuamente através dos poços. Sua espessura diminui para norte, não tendo sido constatada na região central além das expressivas muralhas de sal que existem a partir do poço SPS-021 (Fig. 5). Volta a se fazer presente na porção norte da bacia, tendo sido constatada no poço RJS-067, mas sua expressão nesta área está ainda por ser determinada.Representa a culminância da fase transgressiva cretácea, sendo cronocorrelata às margas do topo da Formação Macaé (Bota) da Bacia de Campos (Mohriak et al. 1995).

O limite inferior da seqüência é representado pela discordância $\mathrm{H} 4$, correspondente à importante queda eustática global ocorrida no Eo-Cenomaniano. A discordância, que coincide com o topo da Formação Itanhaém, nem sempre é de fácil rastreamento regional porque os refletores acima e abaixo são freqüentemente paralelos, mas em muitas sísmicas seções pode-se observar terminações da seqüência cenomaniana/eoturoniana em downlap sobre a seqüência neoalbiana. Segundo Pereira (1994), trata-se de uma desconformidade, sobre a qual se depositaram arenitos turbiditicos de trato de mar baixo.

O empilhamento estratigráfico é transgressivo, com padrão de refletores em onlap, indicativo de subida relativa do nível do mar. Em perfis de raios gama dos poços, o padrão da curva é serrilhado e a seqüência mostra aumento nos valores de radioatividade em direção ao topo, o que é reflexo de aumento na argilosidade. A transgressão propiciou o estabelecimento de condições anóxicas, especialmente no Eo-Turoniano quando do pico máximo da transgressão. Os folhelhos ricos em matéria orgânica (teores de até 3\%) que se manifestam como refletores sísmicos fortes no topo da seqüência, onde está situada a superfície de inundação máxima, constituem, segundo Viviers (1986), o registro do segundo evento anóxico global (OEA2) de Arthur \& Schlanger (1979). O trato transgressivo foi fortemente influenciado por aporte de sedimentos de origem terrestre, já que a matéria orgânica é predominantemente do tipo 3.

Turoniano Superior/Santoniano Inferior (H5-H6) Esta seqüência também é predominantemente pelítica, mas, ao contrário da seqüência sotoposta, apresenta porcentagens baixas de matéria orgânica nos folhelhos, também do tipo 3 denotando influência continental. Sua base é definida por H5 que é uma importante desconformidade de idade turoniana, com erosão subaérea nas partes proximais, com truncamentos generalizados, tanto na região plataformal como na bacinal, além de mudanças acentuadas nos sistemas e regimes deposicionais (Pereira 1994).

Os refletores internos da seqüência apresentam significativo downlap sobre $\mathrm{H} 5$ em suas porções mais profundas, com terminações de clinoformas sobre folhelhos marinhos profundos da seqüência sotoposta. $\mathrm{Na}$ base das clinoformas existem corpos de arenitos turbiditíticos, que representem depósitos de leques submarinos. Os turbiditos foram formados apenas nas partes mais profundas durante queda do nível do mar, constituindo leques turbidíticos de assoalho e de talude. Tais sistemas constituem depósitos de trato de mar baixo inicial, conforme modelos da estratigrafia de seqüências da escola da Exxon (Vail et al. 1991). Tais depósitos podem ter sido formados, entretanto, durante o descenso do nível do mar, sendo mais apropriadamente considerados como trato de sistemas de queda, conforme modelos propostos por Hunt \& Tucker (1992) e Plint \& Nummedal (2000).

Os arenitos turbidíticos, classificados como Membro Ilhabela da Formação Itajaí-Açu, são importantes rochas-reservatório para a geologia do petróleo da Bacia de Santos. Ocorrem principalmente na chamada "Calha Central", uma depressão situada na retaguarda do primeiro alinhamento de muralhas e domos de sal perfurantes. A calha foi formada com o deslocamento do sal no sentido offshore e formação de estruturas halocinéticas nas partes mais distais da bacia, processo que gerou espaço de acomodação significativo na retaguarda dos diápiros. A calha central da bacia apresenta intercalações significativas de arenitos turbidíticos com padrão em caixa nos perfis de raios gama, constituindo os reservatórios das acumulações do campo de Merluza (Fig. 7).

A seqüência apresenta suas maiores espessuras na parte sul da bacia, onde predominam depósitos marinhos plataformais (Fig. 5). Na parte norte da bacia, onde as espessuras são menores e existem intercalações de rochas vulcânicas básicas, também podem ser encontradas ocorrências de turbiditos (como nos poços BSS-062 e SPS-15).

Santoniano Superior/Campaniano Inferior (H6-H7) $\mathrm{O}$ limite inferior, definido pelo discordância H6, corresponde a uma expressiva desconformidade, gerada em grande parte em condições subaéreas. $\mathrm{O}$ contato discordante é indicado pelo truncamento de refletores das seqüências sotopostas. A seção marinha sotoposta foi exposta e parcialmente erodida devido ao abaixamento relativo do nível do mar, e os sedimentos transportados mergulho deposicional abaixo, depositando-se nas calhas que anteriormente eram sítios de deposição dos turbiditos Ilhabela. Assim, áreas anteriormente mais profundas, onde se depositaram anteriormente os turbiditos Ilhabela, passaram a ser sítios de progradaçoes deltaicas de trato de sistemas de mar baixo. Os deltas apresentam típico padrão de granocrescência ascendente em perfis de raios gama. atravessados pelos poços SPS-8 e SPS-9.

A parte superior da seqüência apresenta maior extensão regional, como pode ser visto na figura 5. Sua base é uma superfície transgressiva regional, que na parte central da bacia recobre os deltas de mar baixo. A seqüência recobre em onlap a plataforma exposta na 


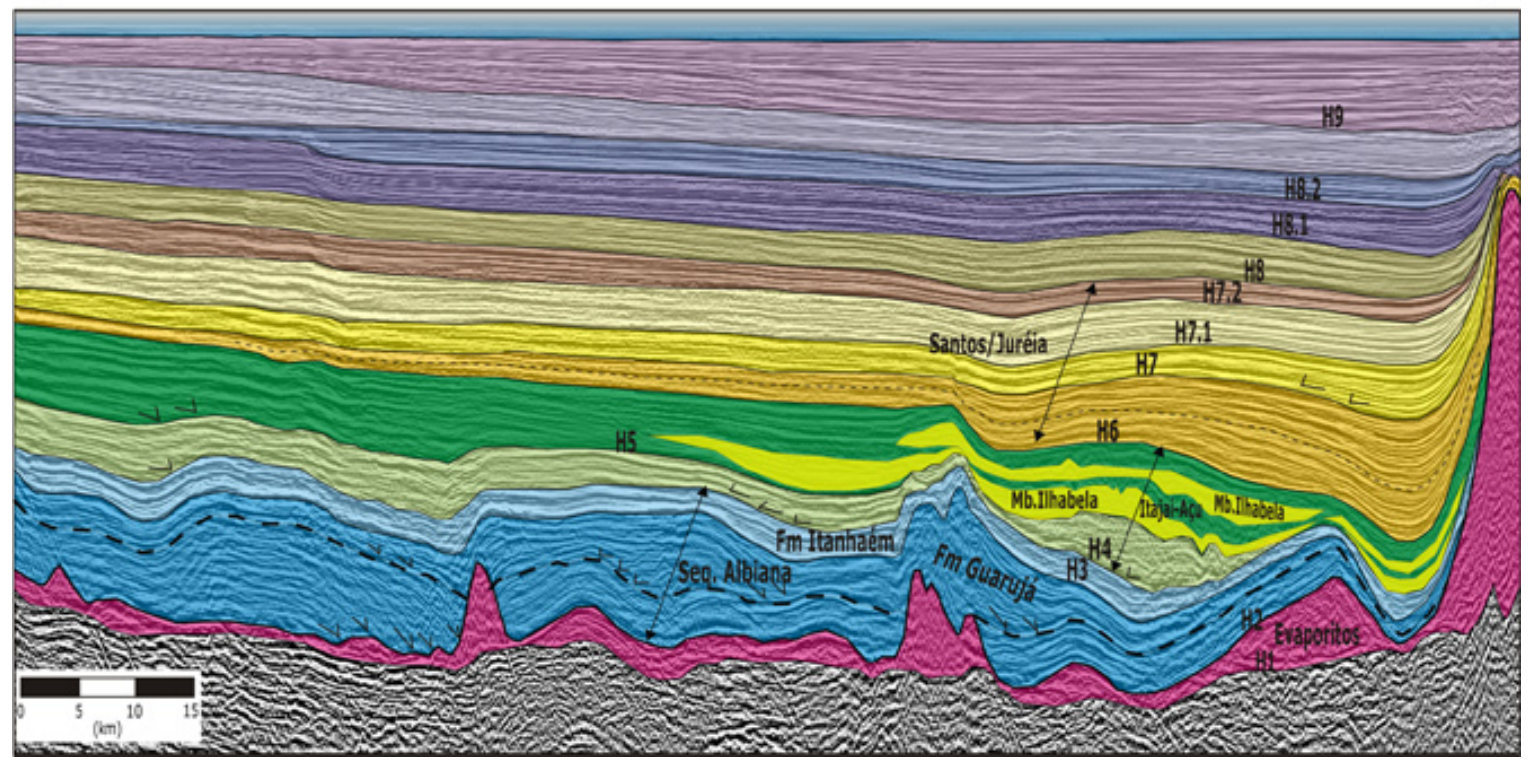

Figura 7 - Arenitos turbiditicos do Membro Ilhabela, formados na parte inferior e na base de clinoformas, em calha deposicional a oeste de muralhas de sal.

parte sul da bacia, sobrepondo folhelhos marinhos turonianos/coniacianos da Formação Itajaí-Açu. Sobre a superfície transgressiva, na base do trato de sistemas transgressivo, ocorrem fácies com altos valores de radioatividade. Os picos radioativos não estão restritos a uma litologia em particular e valores de radioatividade altos são observados também em arenitos e conglomerados, que constituem fácies costeiras retrabalhadas por ondas e correntes. $\mathrm{O}$ intervalo radioativo tem poucas dezenas de metros e pode ser rastreado na região plataformal da parte sul (poço BSS-82-A) até parte central da bacia (poço SPS-15).

A parte superior da seqüência é caracterizada por refletores com padrão divergente para as partes mais distais da bacia. A arquitetura estratigráfica é marcada por onlap costeiro e progradação de sistemas aluviais e costeiros com nível relativo do mar subindo, constituindo trato de sistemas de mar alto.

A rápida progradação de sistemas siliciclásticos aluviais/costeiros registra mudança marcante no padrão de preenchimento sedimentar da Bacia de Santos a partir do Santoniano. Como conseqüência, sedimentos terrígenos grossos avançaram bacia adentro, vindo a constituir os arenitos e conglomerados das formações Santos e Juréia, a primeira mais proximal em relação à segunda. A seção de conglomerados e arenitos grada para fácies de siltitos e folhelhos em direção às partes mais distais da bacia, seção que tem sido referida como Formação Itajaí-Açu (parte superior).

Campaniano Superior (H7-H7.1) O limite inferior da seqüência é definido pela discordância $\mathrm{H}$ 7, uma importante discordância erosiva (desconformidade), com exposição subaérea e deslocamento do onlap costeiro. Trata-se de uma discordância de expressão regional na área da atual plataforma, que transiciona para conformidades correlatas em porções situadas mais para o interior da bacia.

A seqüência campaniana é composta por depósitos pertencentes às formações Santos (proximal), Juréia (intermediária) e Itajaí-Açu (distal). Caracteriza-se pela progradação de sistemas costeiros com nível relativo do mar subindo (onlap costeiro). As maiores espessuras da seqüência encontram-se na calha central da bacia, onde existem grandes cunhas progradacionais no bloco baixo da falha de Cabo Frio. Na parte inferior das clinoformas, que jazem em downlap sobre H7, podem ocorrer arenitos turbidíticos intercalados na seção pelítica marinha da Formação Itajaí-Açu.

Maastrichtiano (H7.1-H7.2) A seqüência maastrichtiana é limitada na sua base pelo discordância H7.1, um refletor sísmico forte, mas sem truncamentos erosivos (Pereira \& Macedo 1990, Pereira 1994). Apresenta a mesma lógica de preenchimento do Campaniano, ou seja, progradação de sistemas costeiros com nível relativo do mar subindo. Caracteriza-se, em seções sísmicas, por refletores com padrão divergente em direção ao centro da bacia e ápice nas proximidades do limite da chaneira de ocorrência do Cretáceo. A seqüência é pouco espessa no sul, tendo depocentro na parte norte da bacia, onde grandes cunhas clásticas progradacionais, muito bem ilustradas nas figuras 4 e 8 , causaram rafting do sal (Mohriak et al. 1995).

Os depósitos de sistemas aluviais e costeiros, que constituem as formações Santos e Juréia, interdigitam-se, no sentido do mergulho deposicional, à seção pelítica marinha da Formação Itajaí-Açu, que forma a parte distal das cunhas clásticas. Nos perfis de poços podem ser reconhecidos ciclos com granocrescên- 


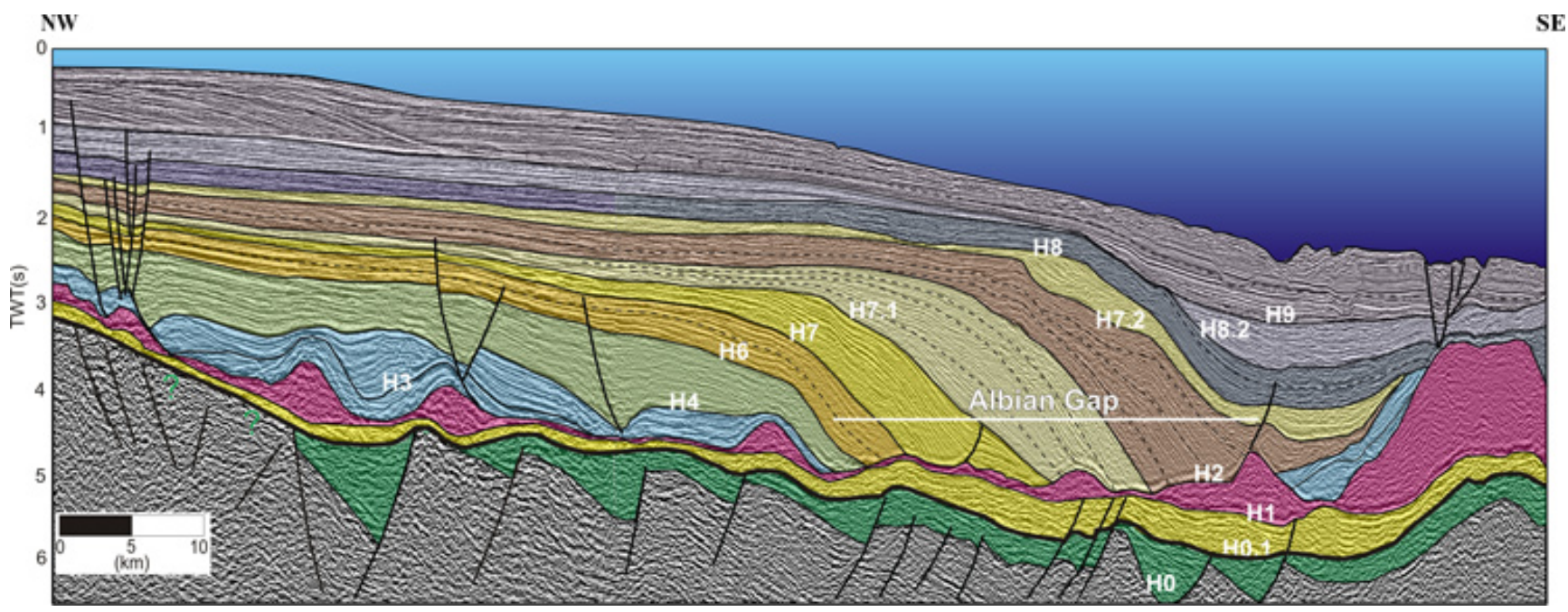

Figura 8 - Grandes clinoformas clásticas do Cretáceo superior a oeste de muralhas de sal. As clinoformas estão rotacionadas em conseqüência do deslocamento do sal. A camada de sal se adelgaça bastante e a seção albiana é rompida e deslocada, configurando feição conhecida como albian gap.

cia ascendente, interpretados como lobos deltaicos. Destaca-se a presença de arenitos com altos valores de radioatividade na parte superior do Cretáceo nos poços 1-BSS-73, 1-SPS-28, 1-BSS-70. Este intervalo com alta radioatividade pode ser rastreado em outras poços, constituindo marco estratigráfico importante.

Turbiditos podem ocorrer na parte basal das cunhas progradacionais, sobre a discordância H7.1, na retaguarda dos domos de sal associados à falha de Cabo Frio, aspecto já ressaltado por Pereira \& Macedo (1990). Dificuldades de trapeamento decorrem de dificuldade de selamento, dadas as características psamíticas do intervalo.

Paleoceno (H7.2-H8) O limite Cretáceo/Terciário é uma desconformidade importante na Bacia de Santos. A discordância H7.2 é marcada por um aumento significativo no tempo de trânsito nos perfis sônicos, indicativo de menor grau de compactação em relação às unidades cretáceas. Nas partes mais distais da bacia, o contato com os depósitos cretáceos é concordante, mas a seção paleocênica passa a ser classificada como Formação Marambaia.

A discordância coincide com importante evento de queda global do nível do mar, de forma que este limite de seqüência está intimamente associado a flutuação eustática negativa. Como conseqüência da queda acentuada do nível do mar, houve um evento muito importante de regressão forçada. Na parte norte e, especialmente, na parte sul da bacia, formaram-se depósitos de leques de assoalho e de talude em trato de sistemas de queda e de mar baixo. Na parte central da bacia esta seção não ocorre, ou é muito pouco espessa, possivelmente devido às estruturas salinas que representaram um obstáculo à passagem de sedimentos para as porções mais profundas.

Na parte superior da seqüência o empilhamen- to é nitidamente transgressivo, com onlap marinho no talude, recobrindo apenas parcialmente os depósitos continentais do prisma costeiro cretáceo, que foi submetido, em suas porções proximais, à erosão subaérea durante o Paleoceno (Figs 3 e 4). Assim, é praticamente inexistente o registro estratigráfico do Paleoceno nas porções mais proximais, já que a seção paleocena está confinada às áreas de águas mais profundas.

Eoceno/Oligoceno Inferior (H8-H8.2) Discordância reginal $\mathrm{H} 8$, associada a importante evento de queda do nível do mar, marca o limite Paleoceno/Eoceno. Devido à ausência de depósitos paleocênicos na área da plataforma continental, a discordância H8 (topo do Paleoceno) coincide com H7.1 (topo do Cretáceo), dificultando o rastreamento do limite Cretáceo/Terciário.

Tratos de queda e de mar baixo marcam a parte inferior do Eoceno, com espessos pacotes de fácies geradas por fluxos de gravidade, entre os quais turbiditos de leques de assoalho. Apresenta espessamento acentuado talude abaixo, a partir do sopé continental, com depocentro principal na área sul da bacia e secundário na área norte. A seção do Eoceno médio e superior é caracterizada pela presença de clinoformas de progradações deltaicas (Moreira et al. 2001), claramente identificadas em seções sísmicas, compondo vários ciclos menores, com transgressões e regressões de menor amplitude.

No topo da seção eocena, caracterizada por clinoformas nas seções sísmicas e por intervalos que mostram ciclos com granocrescência ascendente em perfis de poços, foi definada a discordância H8.1, interpretada como uma superfície transgressiva, sobrepondo as seções deltaicas do Eoceno.

A sucessão estratigráfica do Oligoceno inferior mostra empilhamento transgressivo, com a implantaçao de plataforma mista siliciclástico-carbonática. Trata-se de transgressão generalizada, havendo o recoabrimento 
em onlap costeiro de áreas muito proximais da bacia com sobreposição direta sobre o embasamento précambriano (Fig. 3). Em alguns casos o onlap é sobre superfície aplainada, em outros sobre superfície aplainada com relevos residuais, tipo inselbergs.

Oligoceno Superior/Mioceno Inferior (H8.2-H9) A discordância basal H8.2 é uma superfície que trunca estratos do Oligoceno inferior. Trata-se de um refletor muito nítido, que pode ser rastreado das partes mais distais até a área da plataforma, onde vai perdendo sua expressão. O horizonte foi correlacionado ao Marco Azul da Bacia de Campos, por apresentar características sísmicas e idade similar às relatadas por Gamboa et al. (1986).

Uma seção basal, onde predominam padrões em onlap marinho recobrindo o talude, ocorre em algumas porções da bacia, especialmente na sua parte sul. Trata-se de sistemas de água profunda, possivelmente leques submarinos de tratos de queda e/ou mar baixo (Figs. 4 e 7). Trata-se de uma seção importante do ponto de vista de possíveis acumulações, especialmente considerando-se a possibilidade de trapas estratigráficas ou mistas em reservatórios turbidíticos, como ocorre na Bacia de Campos. Infelizmente, não tivemos acesso de informações de poços que permitissem caracterização faciológica dos depósitos.

Durante a deposição da seqüência o nível relativo do mar continuou subindo, o que é deduzido pela existência de padrões de terminação de estratos em onlap costeiro sobre a plataforma. Clinoformas deltaicas eo-miocênicos podem ser observados em algumas seções sísmicas, principalmente na parte sul da bacia, representam deltas de tratos de sistemas de mar alto, Apesar de pequenos avanços e recuos dos sistemas deltaicos, a linha de costa permaneceu, durante o intervalo de tempo da seqüência, aproximadamente na posição da atual quebra da plataforma.

Mioceno Superior/Recente (H-9-H10) De idade meso-miocênica, a discordância H9 tem expressão bacinal, com exposição subaérea e vales incisos na plataforma. Em algumas seções sísmicas, há evidências de erosão das sigmóides dos deltas de mar alto do Mioceno inferior, com a presença de vales incisos e um brusco deslocamento da linha de costa em direção ao oceano (regressão forçada). Como resultado, clásticos grossos adentraram na bacia, fato comprovado pela existência de conglomerados no intervalo 1650 a $1750 \mathrm{~m}$ no poço 1-SCS-01.

A arquitetura estratigráfica da seqüência é caracterizada pela existência de várias descontinuidades e conjuntos de clinoformas progradacionais, delineando vários ciclos estratigráficos de $4^{\mathrm{a}}$ ordem. $\mathrm{O}$ empilhamento estratigráfico é ora agradacional, ora progradacional, com grandes clinoformas com terminações basais em downlap sobre H9, e espessamento acentuado na parte sul da Bacia de Santos. Há progressivo deslocamento da paleolinha de costa em direção ao oceano, evidenciando progradação do talude.
O preenchimento é complexo em bacia com fisiografia de plataforma e talude, havendo rrecorrência de plataformas silicicláticas (Formação Marambaia) e carbonáticas (Formação Iguape), resultado de flutuações climáticas e do nível do mar, decorrentes de ciclos globais de glaciação. As plataformas carbonáticas da Formação Iguape são bem desenvolvidas na parte sul da bacia, tendo sido originadas principalmente nos períodos de clima mais quente e de nível do mar em elevação, quando o aporte terrígeno foi reduzido.

Flutuações eustáticas foram muito acentuadas devido ter sido o período caracterizado pela ocorrência global de ciclos glaciais. Durante períodos glaciais o nível do mar em queda promoveu exposição das plataformas e passagem de terrígenos para além das margens externas das plataformas carbonáticas, que geraram sistemas turbidíticos no talude e sopé continentais. Sobre os depósitos turbidíticos de águas profundas progradaram deltas de tratos de sistemas de mar baixo, que promoveram acentuada regressão marinha. Seus prodeltas são espessos e íngremes, freqüentemente sujeitos a escorregamentos e falhas lístricas de crescimento. Movimentos de massa produziram também fluxos de detritos e correntes de turbidez, gerando fácies produzidas por fluxos gravitacionais no prodelta. São deltas de borda de plataforma, que ocuparam espaço de acomodação criado na frente das plataformas carbonáticas. Nas seções são nítidas terminações em downlap sobre o limite inferior das seqüências deposicionais e em onlap contra o edifício das carbonatos.

MIGRAÇÃO DOS DEPOCENTROS A sedimentação dos evaporitos aptianos ocorreu sobre a superfície de discordância H1, que se apresentava com morfologia relativamente plana, sem grandes irregularidades. Com a ruptura de Gonduana e deriva continental em curso, uma charneira flexural se delineou originando uma bacia com fisiografia de rampa.

No Albiano houve incremento acentuado do espaço de acomodação devido à subsidência diferencial, com a formação da geometria em rampa, e à subida eustática do nível do mar. O movimento do sal talude abaixo, com retirada de massa da área da rampa, incrementou ainda mais o espaço de acomodação. A presença de incipiente charneira se torna evidente a partir do Eo-Albiano, condicionando, ao menos em parte, a arquitetura estratigráfica da seqüência $\mathrm{H} 2-\mathrm{H} 3$ (trato deposicional constituído pelas formações Guarujá/Florianópolis), que em algumas seções mostra visível acunhamento para leste, não ultrapassando a linha de charneira. Na seqüência neo-albiana $\mathrm{H} 3-\mathrm{H} 4$ (trato deposicional Itanhaém/Florianópolis), a arquitetura estratigráfica é caracterizada por empilhamento retrogradacional, com recobrimento progressivo em onlap costeiro sobre a superfície da rampa. Isto resultou de incremento acentuado do espaço de acomodação, não só pela subsidência flexural da bacia, mas também pela elevação eustática do nível do mar. Não foi possível determinar com exatidão o depocentro das duas seqüências albianas, por dois motivos principais: 1) não 
há número suficiente de poços que tenham atravessado a seção; 2) a seção encontra-se segmentada pelo rafting decorrente do movimento do sal. Os dados disponívieis sugerem que o depocentro estaria situado na porção sul da bacia, onde estão os principais campos que produzem nos reservatórios carbonáticos albianos, mas somente um acurado mapeamento sísmico e restaurações de seções poderiam fornecer informações para que se estabeleça com mais exatidão o depocentro durante o Albiano.

A partir do Cenomaniano, contínua subsidência flexural da rampa, com pólo na área da charneira, gerou espaço de acomodação para a deposição de diversas seqüências deposicionais do Cretáceo superior. Áreas a oeste da charneira foram submetidas a processos de desnudação no Neo-Cretáceo, fornecendo sedimentos que foram depositados a leste, ocupando espaço de acomodação criado pela subsidência do substrato da bacia. Devido a isto, o estratos neocretáceos não ocorrem na região da plataforma, a leste da charneira, encontrando-se presente apenas na parte mais profunda da bacia (Fig. 3).

A charneira flexural é hoje elemento notável no arcabouço da bacia, separando uma plataforma na porção proximal, com leve inclinação para leste $\left(<1^{\circ}\right)$, de uma rampa que mergulha também para leste, porém com inclinação variável de 4 a $6^{\circ}$. Por isso, a superfície de discordância $\mathrm{H} 1$ apresenta-se inclinada no sentido offshore até a Zona de Falha de Cabo Frio, a partir de onde ocorre inversão de seu mergulho (Figs. 3 e 4).

A arquitetura estratigráfica da seqüência cenomaniana/eo-turoniana $(\mathrm{H} 4-\mathrm{H} 5)$ também é retrogradacional, da discordância $\mathrm{H} 4$ à superfície de inundação máxima gerada quando o nível do mar atingiu pico máximo na metade do Turoniano. Uma configuração fisiográfica de plataforma e talude já tinha se instalado na bacia, pelo menos em sua porção sul, onde está o depocentro da seqüência cenomaniana/eo-turoniana. Condições de anoxia prevaleceram no talude durante o Turoniano, responsáveis pela preservação da matéria orgânica nos folhelhos da Formação Itajaí-Açu, cujo teor de carbono orgânico total atinge valores de até $3 \%$.

Queda expressiva do nível do mar, que é reconhecida globalmente, ocorreu na Bacia de Santos após a superfície de inundação máxima no Turoniano. As áreas da plataforma foram palco de extensiva erosão no Neo-Turoniano, sendo os sedimentos carreados para o incipiente talude recém-instalado, indo formar os turbiditos Ilhabela nas calhas deposicionais criadas pelo deslocamento do sal em direção ao oceano. Terminações dos refletores revelam padrão em onlap costeiro para o restante da seqüência, indicando empilhamento retrogradacional e subida do nível do mar.

Do Santoniano até o final do Cretáceo (Maastrichtiano), o aporte sedimentar foi muito alto, com deposição de espessa seção sedimentar terrígena, compondo três seqüências regressivas, separadas por quedas do nível de base que geraram desconformidades no Eo-Campaniano e Eo-Maastrichtiano. Grandes sistemas aluviais progradaram bacia adentro formando imensos prismas costeiros e causando regressão da linha de costa, que avançou para o oceano cerca de 250 $\mathrm{km}$ em relação à sua atual posição. A regressão deposicional ocorreu em condições de subida do nível relativo do mar, o que se reflete nas terminações em onlap costeiro, visíveis nas seções sísmicas (Fig. 8). A seqüências neocretáceas adelgaçam-se mergulho acima, desaparecendo por acunhamento antes de atingir a charneira.

A possança dos depósitos do intervalo NeoSantoniano/Maastrichtiano é muito grande, atingindo espessura da ordem de $3000 \mathrm{~m}$. Considerando que o nível do mar permaneceu alto, o impressionante aumento no espaço de acomodação foi conseqüência, não só do incremento na taxa de subsidência, fenômeno diretamente relacionado à tectônica pós-rifte, mas principalmente pela continua movimentação do sal talude abaixo, o que se manifestou sobretudo na parte norte da bacia. As formações Santos e Juréia constituem o registro sedimentar de importantes eventos de incremento do suprimento sedimentar na bacia, responsável pela formação de fácies de conglomerados. As cunhas progradacionais estão relacionadas à reativação tectônica da área-fonte a partir do Santoniano, que constitue evento tectônico ímpar na margem continental brasileira (Pereira et al. 1986, Macedo 1989, Cobbold et al. 2001, Modica \& Brush 2004). O tectonismo foi associado a importantes pulsos de magmatismo na bacia, comporovado pela existência de rochas intrusivas e vulcânicas, principalmente na parte norte da bacia, onde há espessos pacotes de vulcânicas e de intrusivas associadas.

A notável progradação, do Santoniano ao Maastrichtiano, criou espessos prismas clásticos de sistemas costeiros (deltas e leques aluviais costeiros), que deram origem à fisiografia de plataforma e talude continentais. A progradação foi muito rápida, acentuando sobremaneira a fuga dos evaporitos para as partes mais distais da bacia, onde foram formadas sucessivas linhas de muralhas de sal. Em determinadas situações, o sal, em seu movimento para as partes distais da bacia, transportou seções sedimentares a ele sobrepostas. Desta forma, segmentos da plataforma carbonática Guarujá, com seções marinhas neoalbianas/turonianas que a recobriam, desgarraram-se e foram deslocados de seus sítios deposicionais, estando hoje isoladas em posições mais distais da bacia

Durante sua viagem a bordo do sal em movimento (rafting), tais seções alóctones não foram recobertas por sedimentos, já que a sedimentação se processava no espaço de acomodação criado nas costas das muralhas de sal. Como decorrência, sobre estes blocos viajantes depositaram-se apenas sedimentos muito mais jovens, sendo o contato por discordância, muitas vezes de natureza angular. Isto porque as seções desgarradas, em seu movimento, deformam-se com a deformação da seção salina subjacente.

A análise da distribuição espacial das diferentes seqüências mostra que ocorreu um deslocamento progressivo do depocentro de sudoeste para nordeste, 
do Cenomaniano ao Maastrichtiano, evidente na seção strike da figura 5. Esta tendência de migração dos depocentros para nordeste foi confirmada pelos mapas de isópacas contruídos para as diferentes seqüências (Fig. 9). A migração dos depocentros foi conseqüência da ação combinada de soerguimento desigual das áreas- fonte, de mudanças nos pontos de suprimento sedimentar e de geração diferencial de espaço de acomodação devido ao deslocamento provocado pela tectônica do sal.

Do Paleoceno ao Eo-Oligoceno (H7.2-H8.2), manteve-se a tendência de migração do depocentro para
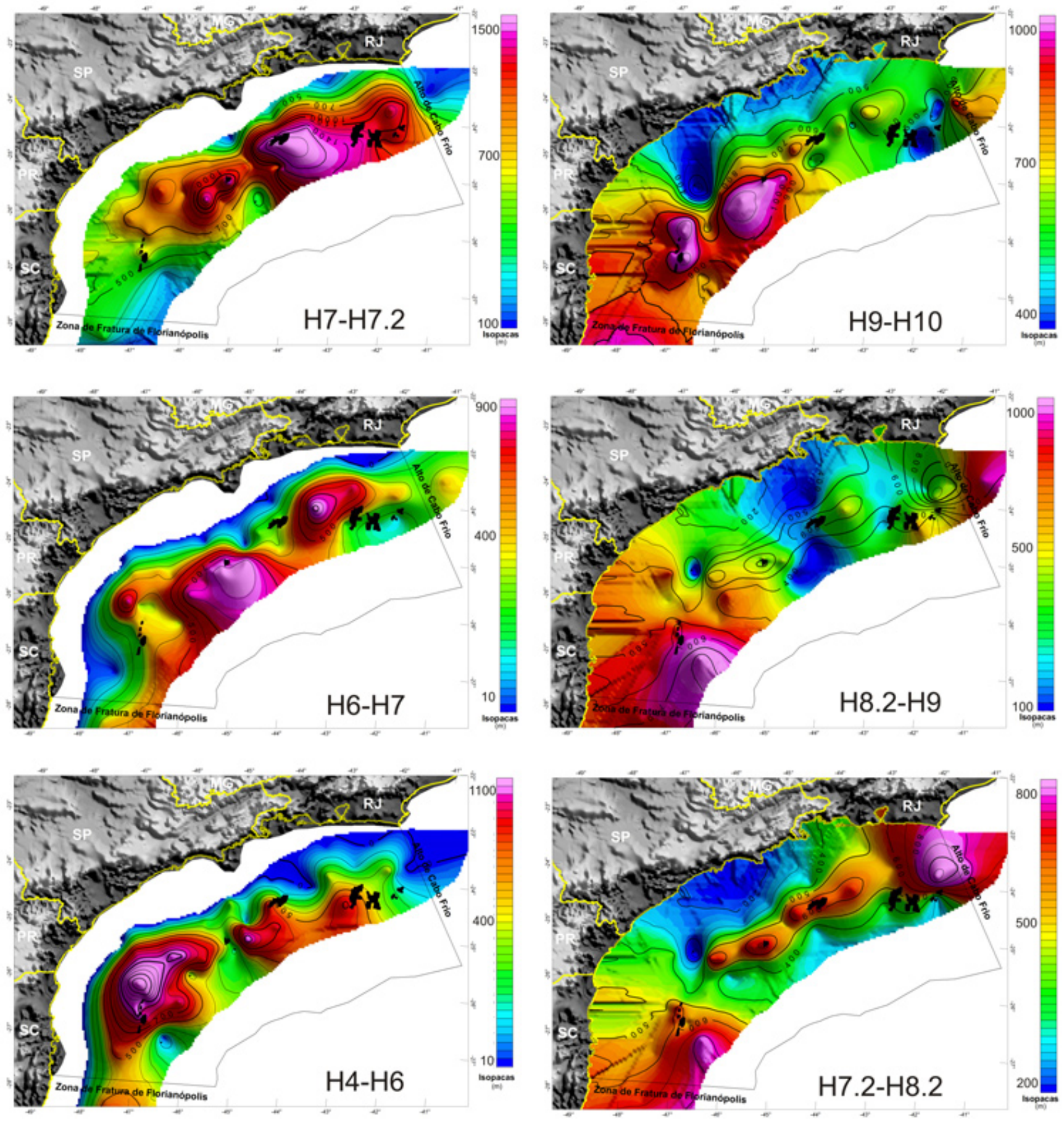

Figura 9 - Mapas de isópacas de diferentes seqüências da Bacia de Santos, mostrando: a) migração dos depocentros para nordeste no Cretáceo superior (H4 a H7.2); b) definição de um depocentro alongado NE/SW na parte central da bacia, que se torna proeminente na porção norte da bacia, no intervalo Paleoceno /Oligoceno inferior (H7.2-H8.2); 3) implantação de importante depocentro terciário na porção sul da bacia (H7.2 a H10). 
nordeste. Neste intervalo de tempo, a sedimentação se concentrou num depocentro alongado na porção central da bacia, com polaridade para nordeste, sendo as maiores espessuras constatadas na área limítrofe com a Bacia de Campos (Fig. 9).

Submetida à contínua erosão, a área da plataforma marginal teve seu relevo aplainado, processo que teve seu clímax na passagem Paleoceno/Eoceno, quando da geração da discordância H8. Desta forma, por erosão, foi configurada a plataforma marginal, que permanece como registro de uma importante superfície de aplainamento, cujo modelado final ocorreu no início do Eoceno.

O Eoceno foi uma época de ativação tectônica, responsável pela formação de prismas costeiros com espessos pacotes de conglomerados de sistemas aluviais. Segundo Moreira et al. (2001), a alta taxa de suprimento sedimentar foi decorrência do soerguimento da Serra do Mar. Na parte norte da bacia, formaram-se sistemas deltaicos de margem de plataforma e depósitos formados por fluxos gravitacionais no talude e bacia (Moreira \& Carminatti 2004). Na parte central da bacia, as muralhas constituíram obstáculos ao avanço para as partes mais distais da bacia. Desta forma, os sedimentos foram transportados para sul, indo formar uma espessa seção de depósitos de fluxos gravitacionais nas partes mais distais.

A partir do Oligoceno ocorreu uma mudança significativa na configuração da bacia, que passou a ter depocentro na sua porção sul (Fig. 9). O intervalo de H8.2 ao fundo do mar comporta muitas discordâncias no registro estratigráfico, mas a mais importante é a desconformidade meso-miocena $\mathrm{H} 9$, associada a importante queda do nível do mar por volta de $11 \mathrm{Ma}$ atrás. O preenchimento sedimentar foi caracterizado pela existência de grandes progradações de sistemas costeiros, com fisiografia característica de plataforma continental e talude. Como resultado de flutuações eustáticas e climáticas, formaram-se sucessões estratigráficas em que depósitos de sistemas siliciclásticos, representados pela Formação Marambaia, intercalamse com fácies de sistemas carbonáticos da Formação Iguape. A progradação de espessos deltas de borda de plataforma deu ensejo a movimentos de massa, talude abaixo, com movimento rotacional de seções no bloco baixo de falhas listricas de crescimento. Fluxos gravitacionais foram responsáveis pela formação de sistemas de leques submarinos em ambiente de bacia profunda.

\section{IMPORTÂNCIA NA EXPLORAÇÃO DE PETRÓ-}

LEO O deslizamento da seção de evaporitos da Formação Ariri teve evolução intimamente associada à evolução longitudinal e transversal das cunhas clásticas progradacionais neo-cretáceas, sobretudo na porção central da Bacia de Santos.

O movimento do sal iniciou-se já no Eo-Albiano durante a deposição dos carbonatos plataformais da Formação Guarujá, o que é evidenciado por "downlaps" de refletores sísmicos em direção ao continente. A deformação inicial é representada por falhas lístricas sintéticas que terminam sobre diápiros de sal gerados no processo, resultando em geometria de blocos basculados e/ou de casca-de-tartaruga. Na porção sul da bacia, almofadas de sal deformaram a seqüência carbonática sobreposta, criando anticlinais com fechamento propício à acumulação de hidrocarbonetos, onde se encontram os campos de Tubarão, Coral, Estrela do Mar, Caravela e Cavalo-Marinho.

O deslocamento do sal não promoveu significativo transporte em jangada (rafting) da seqüência albiana até o início do Santoniano, sendo a dinâmica dominada principalmente por blocos rotacionados e rollovers. Mesmo assim, no intervalo Cenomaniano/ Turoniano foi gerado o primeiro albian gap (AG-1), ou seja, uma área onde a seção de evaporitos está ausente e/ou apresenta pequena espessura devido ao deslocamento do sal talude abaixo (Fig. 10). No AG-1, rotação dos blocos sobre as falhas lístricas criou espaço de acomodação no bloco baixo da Zona de Falha de Merlu$\mathrm{za}$, onde foram depositados turbiditos pertencentes ao Membro Ilhabela da Formação Itajaí-Açu, que constituem os reservatórios das acumulações de petróleo dos campos de Merluza e Lagosta.

Fuga acentuada do sal para posições mais distais da bacia durante o Santoniano, com descolamento e deslocamento da seção sobreposta, causou rafting da seqüência de carbonatos albianos por mais de $20 \mathrm{~km}$ no sentido leste. $\mathrm{O}$ avanço progressivo das cunhas clásticas promoveu a retirada quase total do sal, criando o segundo albian gap (AG-2), mais extenso que o primeiro e limitado a leste pelas estruturas da Zona de Falha de Cabo Frio (Fig. 10).

O processo de rafting produziu relações estratais interessantes para acumulações de petróleo em camadas do Cretáceo superior. De um lado, as cunhas progradacionais são muito espessas, com turbiditos na base de grandes clinoformas deposicionais, havendo possibilidade de camadas com boas características em termos de reservatório. Além disso, as camadas podem acunhar mergulho acima na seção de folhelhos da Formação Itajaí-Açu, ou serem truncadas por falhas, favorecendo a existência de armadilhas mistas. De outra parte, conjuntos de clinoformas tiveram inclinação acentuada pela saída do sal, o que propiciou a formação de homoclinais favoráveis à migração de hidrocarbonetos. Por último, como conseqüência da retirada do sal, a base das clinoformas pode assentar em downlap sobre unidades pré-sal, colocando rochas geradoras do Cretáceo inferior em contato direto com rochas reservatório do Cretáceo superior (Fig. 8).

O espaço criado na área do AG-2 foi preenchido por cunhas clásticas progradacionais neo-cretáceas (formações Santos, Juréia e Itajaí-Açu). O grande acúmulo de sedimentos resultou em subsidência diferencial por sobrecarga, causando soterramento das camadas do Cretáceo inferior a profundidades superiores a $6000 \mathrm{~m}$, onde atingiram a janela de geração de gás. $\mathrm{O}$ acréscimo de temperatura e pressão, devido ao grande soterramento, favoreceu maturação precoce em relação às áreas de ocorrência em águas ultra-profundas, onde 

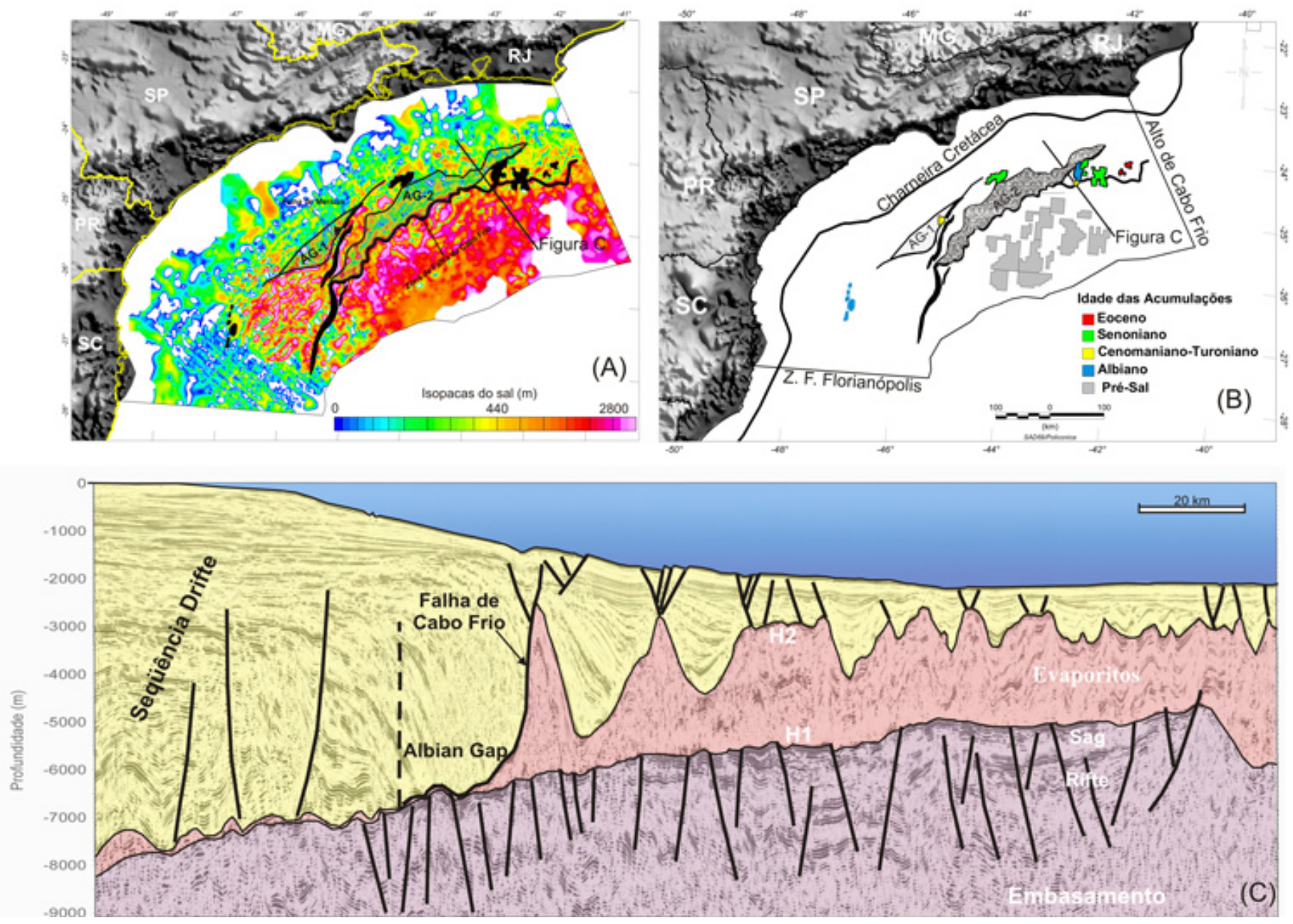

Figura 10 - Áreas onde a seção do Albiano está ausente (albian gap $=A G-1$ e AG-2) e as cunhas progradacionais do Cretáceo superior sobrepõem diretamente seqüências do Cretáceo inferior (portadoras de rochas geradoras). A-B) campos mostram distribuição geral de idade de sudoeste para nordeste, seguindo tendência da migração dos depocentros (blocos no pré-sal indicam áreas potenciais, não necessariamente com descobertas); C) seção sísmica mostrando o albian gap, a inclinação da base do sal para oeste, e seção pré-sal mais rasa em águas profundas, sob espessa seqüência evaporítica (seção sísmica em profundidade, WesternGeco/TGS, AAPG Explorer v.28, n.7, 2007).

a seção do Cretáceo inferior encontra-se mais rasa. Modelagens geoquímicas (Chang et al. 2008) indicam que a geração de hidrocarbonetos, na área da plataforma e do talude continentais, tiveram ápice entre o Campaniano e Maastrichtiano (70-90 Ma).

Os hidrocarbonetos gerados migraram através de falhas e de camadas carreadoras (carrier-beds) até reservatórios siliciclásticos do Cretáceo superior. Armadilhas localizadas sobre diápiros de sal, com fechamento mergulho acima definido por falhas associadas à tectônica salina, são estruturas favoráveis à acumulação. O campo de gás de Mexilhão é exemplo de acumulação de hidrocarbonetos neste play, cuja origem é associada ao AG-2.

Considerando que o timing do processo de rafting foi intimamente associado à progradação das clinoformas, e que estas mostram idades cada vez mais jovens de sudoeste para nordeste no Cretáceo superior, o mapeamento dos depocentros constitui ferramenta importante como guia exploratório para a prospecção de hidrocarbonetos. Um aspecto interessante é que as clinorformas se superpõem na direção offshore, resultando num deslocamento da linha de costa da ordem de dezenas de quilômetros. Os depósitos neo-cretáceos recobrem toda a janela do albian gap, constituindo área favorável para acumulações em trapas estratigráficas e mistas.

A tendência de migração dos depocentros para nordeste se manteve no Paleógeno. A seção do Paleoceno ao Oligoceno, que é pouco espessa na parte central da bacia, apresenta depocentro na porção norte. Este depocentro é caracterizado pela presença de depósitos formados por fluxos gravitacionais nas terminações de clinoformas, constituindo intervalo bastante favorável para acumulações de hidrocarbonetos, à semelhança do que ocorre na Bacia de Campos.

Vale ressaltar a existência de um outro depocentro na porção sul da Bacia de Santos, presente durante todo o Terciário, alterando o padrão de migração para nordeste. Sismofácies são indicativas da presença 
de depósitos produzidos por fluxos gravitacionais em ambientes de água profunda, podendo comportar bons reservatórios, mas que não foram ainda suficientemente investigados.

Um aspecto relevante, derivado do estilo do preenchimento sedimentar delineado acima, é a inversão da inclinação da superfície da base do sal (H1) em direção ao continente, devido à sobrecarga do prisma sedimentar (Fig. 10-C). A inversão implica que, na área do albian gap, as rochas geradoras (situadas abaixo da seção evaporítica) se encontram em profundidades muito superiores às áreas de sua ocorrência em águas ultra-profundas. Este fato ajuda a entender porque na área do albian gap as ocorrências são predominantemente de gás, enquanto que as recentes descobertas na seqüência pré-sal, em águas ultra-profundas, têm sido de óleo leve (campos de Tupi, Carioca e outros).

A seção evaporítica é bastante espessa em águas ultra-profundas, ultrapassando $2000 \mathrm{~m}$. Espessura de tal magnitude foi conseqüência tanto do deslocamento do sal das porções mais proximais, quanto do fato de que a área era um depocentro original da bacia evaporitica (Gamboa et al. 2008). Além de funcionar como selante efetivo, os evaporitos apresentam alta condutividade térmica (Melo et al. 1995, Garcia 2008), o que permite a transferência de calor do topo dos reservatórios para porções mais rasas, retardando o craqueamento térmico dos hidrocarbonetos armazenados na seção pré-sal. Este conjunto de fatores propicia um habitat adequado para a preservação de petróleo de boa qualidade.

CONSIDERAÇÕES FINAIS Do ponto de vista da terminologia litoestratigráfica, verificou-se que a utilização de algumas denominações da seção do Cretáceo superior e do Terciário deve ser feita com cautela, uma vez quer podem induzir erros e dificuldades na comunicação geológica. A Formação Itajaí-Açu, por exemplo, apresenta alguns problemas. De acordo com a carta estratigráfica da bacia (Fig. 2), classifica-se como Formação Itajaí-Açu seções diversas, a saber: a) a seção cenomaniano/eo-turoniano, predominantemente constituída por folhelhos marinhos transgressivos; b) a seção neo-turoniana/eo-santoniana, portadora de folhelhos marinhos com arenitos turbidíticos; e c) seção pelítica neo-santoniana/maastrichitiana, lateralmente interdigitada com os arenitos da Formação Juréia.

Englobando-se uma seção tão diversificada dentro da Formação Itajaí-Açu, fica claro que a denominação deixa de ter significado, pouco contribuindo para a comunicação geológica. Por isso, considera-se que deva haver uma revisão litoestratigráfica, restringindo-se a denominação apenas à seção cenomaniana/ eo-santoniana (intervalo H4-H6), buscando-se outra denominação para o pacote superior. Da mesma forma, sugere-se que a denominação Membro Ilhabela da Formação Itajaí-Açu, que segundo a carta da figura 2 deve ser aplicada a todos os arenitos intercalados nos folhelhos neocretáceos (do Cenomaniano ao Maastrichtiano), fique restrita aos arenitos turbidíticos do intervalo H4H6.

As formações Santos e Juréia são duas unidades clásticas psamíticas, lateralmente contíguas, diferenciadas apenas pelo fato da Formação Santos apresentar arenitos mais grossos e intercalações de conglomerados. O contato entre elas é transicional, portanto seu posicionamento é arbitrário. Sugere-se sejam consideradas em conjunto como Formação Santos/Juréia.

Agradecimentos Os autores agradecem o apoio recebido da Agência Nacional de Petróleo (ANP), da Fundação para o Desenvolvimento da UNESP (FUNDUNESP) e do Laboratório de Estudos de Bacias (LEBAC/UNESP). Os autores são gratos também a inúmeros pesquisadores que atuaram no convênio ANP/ FUNDUNESP (2001-2006) e que muito contribuíram para alcançar os resultados apresentados neste trabalho. Mario Luis Assine e Chang Hung Kiang agradecem ao $\mathrm{CNPq}$ pela concessão de Bolsa Produtividade em Pesquisa.

\section{Referências}

Arthur M.A. \& Schlanger S.O. 1979. Cretaceous Oceanic Anoxic Events as causal factors in development of reefreservoired giant oil fields. AAPG Bulletin, 63:870-885.

Chang H.K., Assine M.L., Corrêa F.S., Tinen J.S., Vidal A.C., Koike L. 2008. Sistemas petrolíferos e modelos de acumulação de hidrocarbonetos na Bacia de Santos. Rev. Bras. Geociências, 38(2-Suplemento):29-46.

Cobbold P.R., Meisling K.E., Mount V.S. 2001. Reactivation of an obliquely rifted margin,Campos and Santos basins, southeastern Brazil. AAPG Bulletin, 85:1925-1944.

Demercian L.S., Szatmari P., Cobbold P.R. 1993. Style and pattern of salt diapirs due to thin-skinned gravitational gliding, Campos and Santos Basin, offshore Brazil. Tectonophysics, 228:393-433.

Gamboa L.A.P., Esteves F.R., Shimabukuro S., Carminatti M., Peres W. E., Souza Cruz C.E. 1986. Evidências de variações de nivel do mar durante o Oligoceno e suas implicações faciológicas. In: SBG, Congresso Brasileiro de Geologia, 34, Goiânia, Anais, v.1, p.8-22.

Gamboa L.A.P., Machado M.A.P., Silva D.P., Freitas J.T.R., Silva S.R.P. 2008. Evaporitos estratificados no Atlântico Sul: interpretação sísmica e controle tectono-estratigráfico na Bacia de Santos. In: Mohriak W., Szatmari P., Anjos S.M.C.d. (ed.) Sal: Geologia e Tectônica. São Paulo, Beca Edições, p. 340-359.

Garcia S.F.d.M. 2008. Fenômenos térmicos associados aos evaporitos. In: Mohriak W.U., Szatmari P., Anjos S.M.C. (eds.) Sal: Geologia e Tectônica. São Paulo, Beca Edições, p.178-187.

Ge H., Jackson M.P.A., Vendeville B.C. 1997. Kinematics and Dynamics of Salt Tectonics Driven by Progradation. AAPG Bulletin, 81:398-423. 
Hunt D. \& Tucker M.E. 1992. Stranded parasequences and the forced regressive wedge systems tract: deposition during base-level fall. Sedimentary Geology, 81:1-9.

Macedo J.M. 1989. Evolução tectônica da Bacia de Santos e áreas continentais adjacentes. Boletim de Geociências da Petrobrás, 3:159-173.

Mello U.T., Karner G.D., Anderson R.A. 1995. Role of salt in restraining the maturation of subsalt source rock. $M a$ rine and Petroleum Geology, 12:697-716.

Modica C.J. \& Brush E.R. 2004. Postrift sequence stratigraphy, paleogeography, and fill history of the deepwater Santos Basin, offshore southeast Brazil. $A A P G$ Bulletin, 88:923-945.

Mohriak W.U., Macedo J.M., Castellani R.T., Rangel H.D., Barros A.Z.N., Latgé M.A.L., Ricci J.A., Mizusaki A.M.P., Szatmari P., Demercian L.S., Rizzo J.G., Aires J.R. 1995. Salt tectonics and structural styles in the deep-water province of the Cabo Frio region, Rio de Janeiro, Brazil. In: Jackson M.P.A., Roberts D.G., Snelson S. (eds.) Salt Tectonics: a global perspective. AAPG (Memoir 65), p. 273-304.

Moreira J.L.P. \& Carminatti M. 2004. Sistemas deposicionais de talude e de bacia no Eoceno da Bacia de Santos. Boletim Geociências Petrobrás, 12:73-87.

Moreira J.L.P., Nalpas T., Joseph P., Guillocheau F. 2001. Stratigraphie sismique de la marge éocène du Nord du bassin de Santos (Brésil): relations plate-forme/systèmes turbiditiques; distorsion des séquences de dépôt. Sciences de la Terre et des planètes/Earth and Planetary Sciences, 332:491-498.

Pereira M.J. 1994. Seqüências deposicionais de $2^{a} / 3^{a}$ ordens (50 a 2,0 Ma) e tectono-estratigrafia no Cretáceo de cinco bacias marginais do Brasil. Comparações com outras áreas do globo e implicações geodinâmicas. Tese de Doutoramento, Instituto de Geociências, Universidade Federal do Rio Grande do Sul, Porto Alegre, 271p.

Pereira M.J., Barbosa C.M., Agra J., Gomes J.B., Aranha
L.G.F., Saito M., Ramos M.A., Carvalho M.D., Stamato M., Bagni O. 1986. Estratigrafia da Bacia de Santos. Análise das seqüências, sistemas deposicionais e revisão litoestratigráfica. In: Congresso Brasileiro de Geologia, 34, Goiânia, Anais, v.1, p.65-79.

Pereira M.J. \& Feijó F.J. 1994. Bacia de Santos. Estratigrafia das Bacias Sedimentares do Brasil. Boletim de Geociências da Petrobrás, 8:219-234.

Pereira M.J. \& Macedo J.M. 1990. A Bacia de Santos: perspectivas de uma nova província petrolífera na plataforma continental sudeste brasileira. Boletim Geociências da Petrobrás, 4:3-11.

Plint A.G. \& Nummedal D. 2000. The falling stage system tract: recognition and importance in sequence stratigraphic analysis. In: Hunt D. \& Gawthorpe R.L. (ed.) Sedimentary response to forced regression. London, Geological Society of London, (Special Publication 172), 1-17.

Szatmari P., Guerra M.C.M., Pequeno M.A. 1996. Genesis of large counter-regional normal faults by flow of Cretaceous salt in the South Atlantic Santos Basin, Brasil. In: Alsop G.I., Blundell D.J., Davison I. (ed.) Salt Tectonics. London, (Geological Society Special Publication 100), p. 259-264.

Vail P.R., Audermard F., Bowman S.A., Eisner P.N., Perez Cruz C. 1991. The stratigraphic signatures of tectonics, eustasy and sedimentology - an overview. In: Einsele G., Ricken W., Seilacher A. (eds.) Cycles and Events in Stratigraphy. Springer-Verlag, p. 617-659.

Viviers M. C. 1986. Bioestratigrafia e evolução paleoambiental do Meso-Neocretáceo da Bacia de Santos, Brasil. In: Congresso Brasileiro de Geologia Goiânia, 34, Anais, v. 1, p.50-62.

Manuscrito BR 23

Submetido em 21 de dezembro de 2007 Aceito em 11 de abril de 2008 